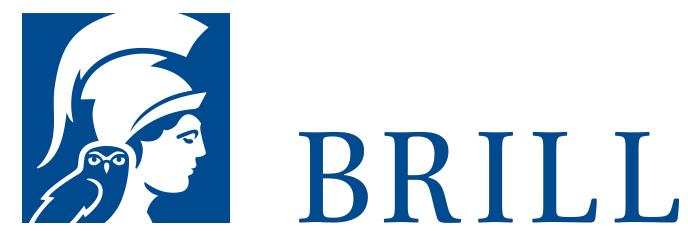

\title{
Collegium Logicum - Logische Grundlagen der Philosophie und der Wissenschaften
}

\section{Band 2}

Author: Godehard Link

Das Werk bietet eine Einführung in die moderne Logik mit Anwendungen in der Philosophie und den Wissenschaften, die mathematischen Standards genügt, zugleich jedoch Wert legt auf Anschaulichkeit und pädagogische Sorgfalt. 'Collegium Logicum' setzt sich mehrere Ziele: 1. Logische Theoriebildung; 2. Philosophische Anwendungen in Sprachphilosophie, Ontologie, Erkenntnistheorie, Philosophie der Mathematik; 3.

Anwendungen in den Wissenschaften: Methodologie (Definitions- und Argumentationslehre, Mengenlehre, Modellierung); Interpretation und Reduktion von Theorien; Wahrscheinlichkeit als Logik der Wissenschaften; Kausalität; 4. Neben der Vermittlung von Standard-Wissen fließen eigene Forschungen in die Darstellung ein, die den Stoff vertiefen und aktuelle Forschungsthemen aufgreifen. Der Band richtet sich an alle, die Kenntnisse in der Logik auf zwei Ebenen erwerben wollen:(i) Logik als formales Instrument zur Modellierung logischer Zusammenhänge sowie (ii) Logik als Gegenstand der Untersuchung (Metalogik). In seiner ausführlichen Darstellungsweise eignet sich das Werk gleichermaßen als Lehrbuch wie für das Selbststudium und führt zugleich an die Forschungsliteratur heran. 'Collegium Logicum' erscheint in zwei Bänden. Band 1 enthält eine Einführung in die klassische Logik bis hin zum Vollständigkeitssatz der Prädikatenlogik. Band 2 erscheint im 1. Quartal 2014 und befaßt sich... See More

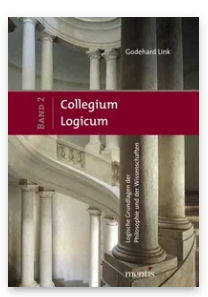

Pages: 723

Seiten

Language:

German

Subjects:

General, Philosophy

Publisher: Brill | mentis

E-Book (PDF)

Released online: 10 Jun 2014

ISBN: 978-3-

89785-075-0

List price

USD \$68.0o

Paperback

Publication date:

10 Jun 2014

ISBN: 978-3-

89785-691-2

List price

USD \$68.0o 
For more information see brill.com

Order information: Order online at brill.com +44330 333 0049 | customerservices@brill.com Submission information: brill.com/authors

Titles published by Brill | Fink, Brill | mentis or Brill | Schöningh: +49(o)715413279216| brill@brocom.de 